\title{
Induction treatments for acute promyelocytic leukemia: a network meta-analysis
}

\author{
Junjie Huang ${ }^{1, *}$, Min Sun ${ }^{2, *}$, Zitong Wang ${ }^{3, *}$, Qiaoxia Zhang ${ }^{1}$, Jin Lou ${ }^{1}$, Yun Cai ${ }^{1}$, \\ Weihong Chen ${ }^{1}$, Xin Du ${ }^{1}$ \\ ${ }^{1}$ Shenzhen Bone Marrow Transplantation Public Service Platform, Department of Hematology, Shenzhen Second People's \\ Hospital, The First Affiliated Hospital of Shenzhen University, Shenzhen 518000, China \\ ${ }^{2}$ Department of General Surgery, Taihe Hospital, Hubei University of Medicine, Shiyan 442000, China \\ ${ }^{3}$ The University of Sydney Medical School, Sydney, NSW 2006, Australia \\ *These authors have contributed equally to this work \\ Correspondence to: Xin Du, email: duxingz@medmail.com.cn
}

Keywords: induction treatment, acute promyelocytic leukemia, network meta-analysis

Received: May 03, 2016 Accepted: September 28, $2016 \quad$ Published: October 04, 2016

\section{ABSTRACT}

Background: 9 treatments for acute promyelocytic leukemia (APL) have been compared in many randomized controlled trials (RCT). The conclusions have been inconsistent and the purpose of this study is to conduct a network meta-analysis.

Results: Rankings of event-free survival are ATRA+RIF (81.2\%), ATRA+ATO $(69.6 \%)$, ATO (50.6\%). Rankings of complete remission are ATRA+RIF $(79.3 \%)$, ATRA+ATO (64.8\%), RIF (60.3\%), ATO (55.9\%). Rankings of avoiding differentiation syndromes are CT $(84.3 \%)$, ATO (80.3\%), RIF (71.6\%), ATRA+RIF (49\%), ATRA+ATO $(40.8 \%)$.

Methods: A total of 1,666 patients from 12 RCTs were enrolled. The frequentist method was used. Relative risks with $95 \%$ confidence intervals were calculated. We produced a network plot, a contribution plot, and a forest plot predictive intervals. The inconsistency factor, the surface under the cumulative ranking curve and the publication bias were evaluated.

Conclusions: ATRA+ATO is eligible to be the first-line treatment for APL. ATRA+RIF is a prospective alternative to the first-line treatment. RIF or ATO should be reconsidered as another option for de novo APL.

\section{INTRODUCTION}

Acute promyelocytic leukemia (APL) is a distinct subtype M3 of acute myeloid leukemia (AML) identified by abnormal promyelocytes and high bleeding risk [1]. Genetically, APL is characterized by a chromosomal translocation $\mathrm{t}(15,17)$ and its formation of promyelocytic leukemia/retinoic acid receptor $\alpha$ (PML-RAR $\alpha$ ) fusion gene encodes the leukemogenic PML-RAR $\alpha$ fusion protein [2]. The protein interferes with the maturation of myeloid cells at the promyelocytic stage, playing a central role in the pathogenesis of APL [3]. APL was the most fatal type of AML six decades ago. Nowadays, however, it has become a highly curable disease [4-6].

The first breakthrough came with the use of cytotoxic chemotherapy (CT) [7]. It helps patients achieve complete remission (CR) yet provided a low overall survival rate due to severe complications [8]. The introduction of differentiation therapy with all-trans retinoic acid (ATRA) rendered remission more easily, but around $30 \%$ of patients would relapse and were often resistant to further treatment with ATRA [9-11]. A subsequent combination of ATRA with chemotherapy raised the event-free survival (EFS) rate [12-14]. In the 1990s, arsenic trioxide (ATO) was initially used to treat relapsed APL patients. Then it was proven to be effective in de novo APL as well [15-17]. Notably, ATRA and ATO target the RAR $\alpha$ and PML moieties of the fusion protein differently $[18,19]$. A combination of these two drugs was observed to have significant improvements in the prognosis of APL by several studies [20-22]. To overcome the limitation that ATO must be intravenously administered during hospitalization, an orally active formulation of arsenic named tetra-arsenic tetra-sulfide 
$\left(\mathrm{AS}_{4} \mathrm{~S}_{4}\right)$ was engineered [23]. Another $\mathrm{As}_{4} \mathrm{~S}_{4}$-containing formula, the Realgar-Indigo naturalis formula (RIF), was developed by several groups in China [24, 25]. Recently, a pilot study shows that the combination of RIF and ATRA is effective, convenient, and economical [26]. In order to compare the efficacy and safety of the different induction treatments for APL, a number of randomized controlled trials (RCTs) were conducted [27-47]. However, the conclusions of these trials have not been completely consistent due to different sample sizes, group characteristics, and clinical settings.

A systematic review and quantitative synthesis of data from different RCTs can be achieved by a metaanalysis. Although several meta-analyses have been published, there are limitations in these traditional meta-analyses [48-50]. They can only combine results from homogeneous studies researching the exact same treatment comparisons. Furthermore, it is not feasible to compare more than two treatments simultaneously. However, a network meta-analysis is able to compare three or more treatments by using a common comparator. In addition, it can synthesize the results of direct and indirect comparisons simultaneously to obtain a more accurate and precise statistical result. Therefore, we aim to perform a network meta-analysis to evaluate different induction treatments for APL.

\section{RESULTS}

\section{Study selection, characteristics and assessment}

As presented in Figure 1, a total of 187 records were initially identified as eligible. 158 irrelevant studies were sorted out as they were non-clinical-trial studies, non-RCT studies, or without interested outcomes. 8 more articles were also excluded by a complete read of the articles, for that they were studies of children, relapsed APL, consolidation or maintenance therapy. Lastly, 21 publications reporting 11 RCTs with a total sample size of 1666 patients were included in this network meta-analysis. Table 1 presents these trials were carried out during 1991 to 2013 in China (6), Europe (4) and the USA (1). Four single-agent treatments of CT, ATRA, ATO and RIF were reported in 2, 6, 3 and 1 studies respectively. Four double-agent treatments of ARTA+CT (4), ATO+CT (1), ATRA+ATO (4) and ATRA+RIF (1) were also studied. Only one study reported on triple-agent treatment of ATRA+ATO+CT.

There are four RCTs with sample sizes of less than 100 and seven RCTs with sample sizes of more than 100 . The features of most RCTs in age, gender and WBC count are not significantly different except for two studies. One study reported only 11 patients and 3 of them were males. Another study included patients with a median WBC count of more than $12.7 \times 10^{9} / \mathrm{L}$. The risk of RCT bias is demonstrated in Figure 2. These RCTs are well- designed in the domain of random sequence generation as only two studies are regarded as to have unclear risks of bias. Most of them did not mention about adequate allocation concealment. As for blinding of participants and personnel, only one study adopted and described the method of blinding. Other studies were open label, which may have resulted in performance bias. In terms of blinding of the outcome assessment domain, nearly all studies are rated as to have an unclear risk of bias. Eight RCTs have a low risk of bias in the domain of incomplete outcome data. Four studies have high risks of bias in terms of selectively reporting results. Two studies have high risks of bias in other biases domain.

\section{Network evidence, contribution and inconsistency}

The evidence-based network is presented in Figure 3. This analysis includes 9 induction treatments for APL, namely CT, ATRA, ATO, RIF, ATRA+CT, ATO+CT, ATRA+ATO, RIF+ATRA, and ATRA+ATO+CT. It can be seen that ATRA, ATRA+ATO and ATRA+CT are the most studied treatments in RCTs, while few RCTs studied RIF, ATO+CT and ATRA+ATO+CT. Notably, although there was only one comparison of CT, its sample size and number of RCTs was relatively large. As for ATO, despite the fact that it was included in three comparisons, its sample size was small. Figure 4 shows the contribution plot for every direct comparison. Among these, 5 comparisons are informed by direct evidence alone (ATO vs. ATO+CT, ATRA vs. CT, ATRA vs. RIF, $\mathrm{ATRA}+\mathrm{ATO}$ vs. ATRA+RIF, ATRA+ATO+CT vs. ATRA+CT), 5 comparisons are by mixed evidence (ATO vs. ATRA, ATO vs. ATRA+ATO, ATRA vs. ATRA+ATO, ATRA vs. ATRA + CT, ATRA+ATO vs. ATRA $+\mathrm{CT}$ ), and 26 comparisons are by indirect evidence alone.

In terms of the overall contribution of the network, ATRA vs. ATRA+CT (16.2\%) and ATO vs. ATRA $(14.5 \%)$ have the most influential evidence. ATRA+ATO vs. ATRA $+\mathrm{CT}(0.1 \%)$ has the least informative direct evidence. As illustrated in Table 2, this network consists of two triangular loops, including (ATO)-(ATRA)$($ ATRA + CT) and (ATRA)-(ATRA+ATO)-(ATRA+CT). The $95 \%$ CI of $I F$ values was truncated at zero at the endpoints of CR $(R o R=1.05,1.10 ; P=0.78,0.36)$, EFS $(R o R=1.38,1.29 ; P=0.42,0.16)$ and DS $(R o R=1.14$, $1,22 ; P=0.95,0.84)$, indicating there is no evidence of significant inconsistency. However, significant heterogeneity was observed in the endpoints of $\mathrm{ED}(I F=$ $0.88 ; R o R=2.41)$, RT $(I F=14.5, R o R=1.98 \mathrm{E}+06)$ and HT $(I F=1.07,0.89 ; R o R=2.92,2.45)$.

\section{Network comparisons, ranks and bias}

Figure 5 shows the estimated summary effects with 95\% CI for all comparisons. Although the confidence intervals and predictive intervals suggest that more RCTs 
Table 1: Characteristics of 11 RCTs enrolled in the network meta-analysis

\begin{tabular}{|c|c|c|c|c|c|c|c|c|}
\hline Trial Name & Trial Year & Country & Author & Comparison & Sample & Age & Male\% & $\begin{array}{c}\text { WBC } \\
\left(\times 10^{9} / \mathrm{L}\right)\end{array}$ \\
\hline APL 91 trial & 1991-1993 & France & Fenaux et al. & ATRA vs. CT & 101 & $40(6-67)$ & $52 \%$ & 2.5 \\
\hline INT0129 & 1992-1995 & America & Tallman et al. & ATRA vs. CT & 346 & $38(1-81)$ & $52 \%$ & 2.1 \\
\hline APL 93 trial & 1993-1996 & France & Fenaux et al. & ATRA vs. ATRA+CT & 208 & $43(2-64)$ & $50 \%$ & 1.3 \\
\hline$A P L R J 96$ & 1996-1998 & China & Niu et al. & ATO vs. ATO+CT & 11 & $41(24-60)$ & $27 \%$ & 2.2 \\
\hline$A P L S X 96$ & 1996-1998 & China & Zhang et al. & ATRA vs. ATO & 75 & $39(12-62)$ & $59 \%$ & 4.3 \\
\hline APL HB 99 & 1999-2002 & China & Ren et al. & $\begin{array}{c}\text { ATRA+CT vs. } \\
\text { ATRA+ATO+CT }\end{array}$ & 95 & $34(14-68)$ & $56 \%$ & 8.1 \\
\hline APL RJ 2001 & 2001-2003 & China & Shen et al. & $\begin{array}{c}\text { ATRA vs. ATO vs. } \\
\text { ATRA+ATO }\end{array}$ & 61 & $39(14-74)$ & $54 \%$ & 7.3 \\
\hline RIF Phase II & 2005-2006 & China & Qian et al. & RIF vs. ATRA & 147 & $37(23-54)$ & $48 \%$ & 12.7 \\
\hline GIMEMA & $2007-2010$ & Italy & Lo-Coco et al. & ATRA+CT vs. ATRA+ATO & 156 & $44(19-70)$ & $49 \%$ & 1.5 \\
\hline RIF Phase III & $2007-2011$ & China & Zhu et al. & ATRA+RIF vs. ATRA+ATO & 231 & $38(15-60)$ & $55 \%$ & 2.1 \\
\hline$A M L 17$ & 2009-2013 & UK & Burnnett et al. & $\mathrm{ATRA}+\mathrm{ATO}$ vs. ATRA+CT & 235 & $47(16-77)$ & $51 \%$ & 2.6 \\
\hline
\end{tabular}

756 potential relevant records identified through database searching of Pubmed, Medline, Cochrane, CNKI, Wanfang and Weipu

187 publications assessed for eligibility

158 publications unqualifiend:

- Not clinical trial studies

- Not RCT studies

- Without interested outcomes

29 publications of randomized controlled trials on the treatments for APL

21 publications of 11 RCTs were included in the current network meta-analysis of the induction treatments for APL.

Figure 1: Flow chart of RCT selection. 
are required for more statistically significant results, the forest plot gives us the impression that the treatments of ATRA+RIF, ATRA+ATO and ATO are more favorable than the other treatments. The induction treatment relative ranking of estimated cumulative probabilities of APL is demonstrated in Figures 6-8. The SUCRA value rankings of EFS are ATRA+RIF (81.2\%), ATRA+ATO (69.6\%), ATO (50.6\%), ATRA+CT (47.8\%), ATO+CT (47.4\%), ATRA (37.6\%), and CT (15.8\%). The SUCRA value rankings of CR are ATRA+RIF (79.3\%), ATRA+ATO (64.8\%), RIF (60.3\%), ATO (55.9\%), ATRA (48.1\%), ATO+CT (43.1\%), ATRA+CT (36.7\%), CT (34.6\%), and $\mathrm{ATRA}+\mathrm{ATO}+\mathrm{CT}(30.0 \%)$. The SUCRA value rankings of avoiding DS are CT (84.3\%), ATO (80.3\%), RIF (71.6\%),
ATRA+RIF (49\%), ATRA+ATO (40.8\%), ATRA+CT (26.4\%), and ATRA (13.1\%).

Figure 9 presents the funnel plot for the network. All the included studies symmetrically distribute around the vertical line $(x=0)$, indicating no significant publication bias in this network analysis.

\section{DISCUSSION}

We adopted different methods to prevent potential bias. RCT methodological quality assessment shows the APL SX 96 (ATRA vs. ATO) trial may have a high risk of bias. However, the evidence network proves that it is not the only study compares ATRA with ATO, reducing

\begin{tabular}{|c|c|c|c|c|c|c|c|c|c|c|c|}
\hline 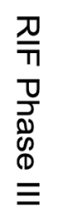 & $\begin{array}{l}\frac{0}{\pi} \\
\frac{0}{0} \\
\frac{0}{0} \\
0 \\
0 \\
=\end{array}$ & 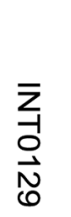 & $\frac{Q}{3}$ & 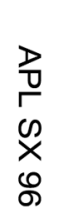 & 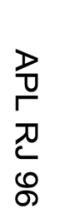 & $\begin{array}{l}\text { D } \\
0 \\
0 \\
0 \\
N \\
\stackrel{8}{0}\end{array}$ & $\begin{array}{l}\text { D } \\
\text { D } \\
\text { I } \\
\text { D } \\
0 \\
0\end{array}$ & $\begin{array}{l}D \\
0 \\
\\
0 \\
\omega \\
\vec{\Xi} \\
\underline{\underline{D}}\end{array}$ & 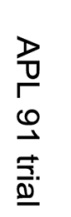 & $\begin{array}{l}\stackrel{b}{3} \\
\stackrel{\vec{V}}{V}\end{array}$ & $\begin{array}{l}+ \text { Low risk of bias } \\
\text { ? Unclear risk of bias } \\
\text { - High risk of bias }\end{array}$ \\
\hline+ & + & + & + & $?$ & $?$ & + & + & + & + & + & Random sequence generation (selection bias) \\
\hline$?$ & + & $?$ & $?$ & $?$ & $?$ & $?$ & $?$ & $?$ & $?$ & $?$ & Allocation concealment (selection bias) \\
\hline$\theta$ & + & - & 0 & - & - & C & - & - & 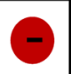 & - & Blinding of participants and personnel (performance bias) \\
\hline$?$ & $?$ & $?$ & $?$ & $?$ & $?$ & $?$ & $?$ & $?$ & $?$ & + & Blinding of outcome assessment (detection bias) \\
\hline+ & + & + & + & $?$ & + & + & $?$ & + & $?$ & $?$ & Incomplete outcome data (attrition bias) \\
\hline+ & 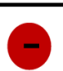 & + & + & - & - & + & - & + & + & + & Selective reporting (reporting bias) \\
\hline$?$ & $?$ & + & + & - & ( & + & $?$ & $?$ & $?$ & + & Other bias \\
\hline
\end{tabular}

Random sequence generation (selection bias) Allocation concealment (selection bias)

Blinding of participants and personnel (performance bias)

Blinding of outcome assessment (detection bias)
Incomplete outcome data (attrition bias)
Selective reporting (reporting bias)
Other bias

Blinding of outcome assessment (detection bias)
Incomplete outcome data (attrition bias)
Selective reporting (reporting bias)
Other bias

Blinding of outcome assessment (detection bias)
Incomplete outcome data (attrition bias)
Selective reporting (reporting bias)
Other bias

Blinding of outcome assessment (detection bias)
Incomplete outcome data (attrition bias)
Selective reporting (reporting bias)
Other bias
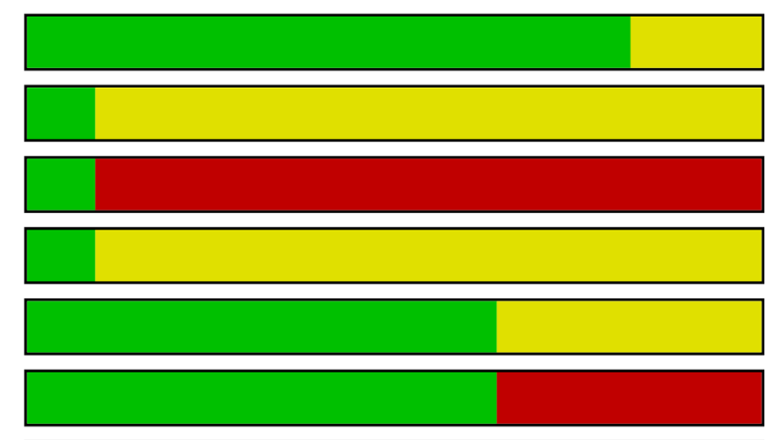

Low risk of bias

Unclear risk of bias

High risk of bias

Figure 2: Risk of bias of the included RCTs. 
Table 2: Results of inconsistency in the network meta-analysis

\begin{tabular}{|c|c|c|c|c|c|}
\hline Endpoints & \multicolumn{1}{c}{ Loop } & $\boldsymbol{I F}(\mathbf{9 5 \%} \mathbf{C I})$ & $\boldsymbol{R o R}(\mathbf{9 5} \% \mathbf{C I})$ & $\boldsymbol{Z}$ test & $\boldsymbol{P z}$ \\
\hline CR & (ATO)-(ATRA)-(ATRA+CT) & $0.05(0.00,0.39)$ & $1.05(1.00,1.47)$ & 0.278 & 0.78 \\
\hline CR & (ATRA)-(ATRA+ATO)-(ATRA+CT) & $0.09(0.00,0.28)$ & $1.10(1.00,1.33)$ & 0.915 & 0.36 \\
\hline ED & (ATRA)-(ATRA+ATO)-(ATRA+CT) & $0.88(0.00,3.91)$ & $2.41(1.00,50.0)$ & 0.752 & 0.45 \\
\hline RT & (ATO)-(ATRA)-(ATRA+CT) & $14.5(13.0,16.0)$ & $1.98 \mathrm{E}+06$ & 19.49 & 0.00 \\
\hline EFS & (ATO)-(ATRA)-(ATRA+CT) & $0.32(0.00,1.10)$ & $1.38(1.00,3.01)$ & 0.802 & 0.42 \\
\hline EFS & (ATRA)-(ATRA+ATO)-(ATRA+CT) & $0.25(0.00,0.61)$ & $1.29(1.00,1.84)$ & 1.391 & 0.16 \\
\hline HT & (ATO)-(ATRA)-(ATRA+CT) & $1.07(0.00,4.51)$ & $2.92(1.00,91.3)$ & 0.610 & 0.54 \\
\hline HT & (ATRA)-(ATRA+ATO)-(ATRA+CT) & $0.89(0.00,3.38)$ & $2.45(1.00,29.2)$ & 0.706 & 0.48 \\
\hline DS & (ATO)-(ATRA)-(ATRA+CT) & $0.13(0.00,4.57)$ & $1.14(1.00,96.8)$ & 0.059 & 0.95 \\
\hline DS & (ATRA)-(ATRA+ATO)-(ATRA+CT) & $0.19(0.00,2.04)$ & $1.22(1.00,7.65)$ & 0.208 & 0.84 \\
\hline
\end{tabular}

Abbreviations: CR, complete remission; ED, early death; RT, remission time; EFS, event free survival; HT, hepatic toxicity; DS, differentiation syndrome; IF, inconsistency factor; RoR, ratio of two odds ratios; CI, confidence interval.

the risk of bias. The contribution plot demonstrates direct comparisons do not influence the entire network significantly (all are below 20\%), including one study with high-risk APL patients (9.3\%). There was none with statistically significant inconsistency in all included endpoints $(P>0.05)$ except for RT $(P=0.00)$. With further evaluation by RoR, HT and ED showed high inconsistency (RoR larger than 2). RT, HT, and ED were therefore excluded in the analysis to ensure the reliability. Adjusted models of SUCRA were adopted to avoid potential bias caused by the small study of APL RJ 96. As no data of DS was obtained in the APL RJ 96, there is no need for an adjusted model to be built. Lastly, the symmetrically distributed funnel plot indicates low risk of publication bias.

In Figures 6-8, the SUCRA values provide the hierarchy for the nine active treatments. ATRA+RIF was observed with the highest ranking in EFS and CR with SUCRA values of $81.2 \%$ and $79.3 \%$, respectively. This is consistent with a recent RCT conducted by Zhu et al. [45]. In 2014, the National Comprehensive Cancer Network adopted ATRA+ATO as first-line treatment for APL [51]. Our results also found that ATRA+ATO can obtain good outcomes in EFS (69.6\%) and CR (64.8\%). In the singleagent induction treatments for APL, using RIF or ATO

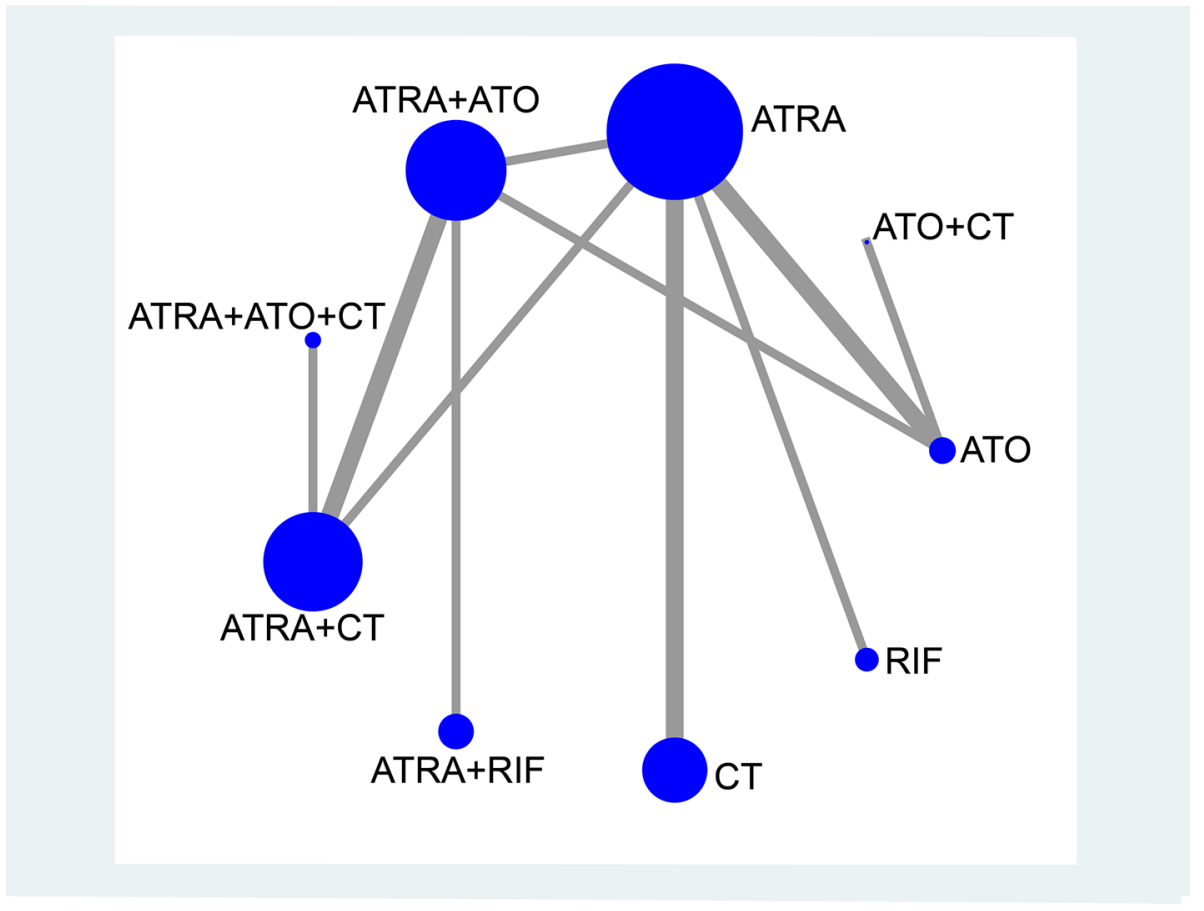

Figure 3: Network plot of treatment comparisons. The size of each node represents the total sample size of treatment. The thickness of each line represents the total number of RCTs that compare each other. Abbreviation: CT, chemotherapy; ATRA, all-trans retinoic acid; ATO, arsenic trioxide; RIF, realgar-Indigo naturalis formula. 
ranks first in EFS and CR compared to using ARTA or CT alone, which also conforms to the previous evidence [52-54]. The analysis also concludes that treatments with additional therapy of CT bring no benefit to EFS and CR. Additionally, treatments without ATRA could avoid DS much better than the ATRA-containing treatments.

Collectively, based on the published materials, RCTs ATRA+ATO is eligible to be first-line treatment for APL. Although ATRA+RIF shows a promising future to be an alternative to the current first-line treatment, more RCTs are required to confirm this suggestion. Another unique finding of our study is that a single agent of RIF or ATO could possibly be reconsidered as another non-inferior option for de novo APL, based on the following meta-analysis results: i) RIF or ATO is proved to be ranked highest among single-agent induction treatments for APL in EFS and CR. ii) There are much less events of differentiation syndrome in the treatment of RIF or ATO. iii) The combination of ATRA with RIF or ATO will increase the adverse events and medical cost, reducing the life quality of patients. However, the sample size of RIF or ATO treatment enrolled in the RCTs is extremely small (with a total of 73 and 27, respectively). More RCTs comparing RIF or ATO to firstline treatment are needed to explore the possibility.

Direct comparisons in the network

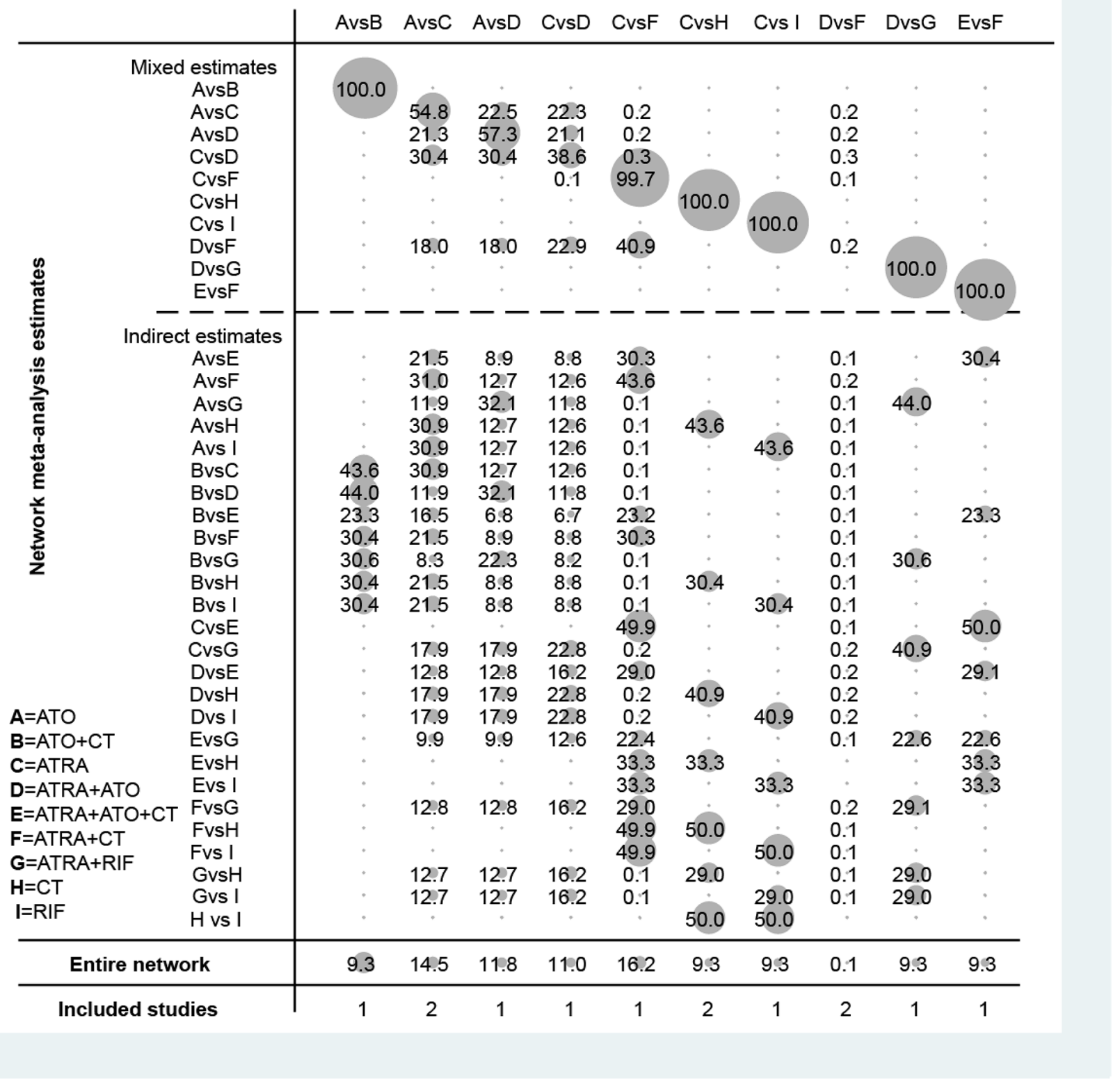

Figure 4: Contribution plot of the included RCTs. The columns refer to the direct comparisons and the rows refer to all possible pairwise comparisons. Abbreviation: A, ATO; B, ATO+CT; C, ATRA; D, ATRA+ATO; E, ATRA+ATO+CT; F, ATRA+CT; G, ATRA+RIF; H, CT; I, RIF. 
In conclusion, the network meta-analysis indicates that ATRA+ATO is eligible to be first-line treatment for APL. ATRA+RIF is a prospective alternative to the ATRA+ATO. RIF or ATO should be reconsidered as an option for de novo APL. More well-designed RCTs are required to confirm these findings.

\section{MATERIALS AND METHODS}

\section{Search strategy and eligibility criteria}

We searched PubMed, MEDLINE, the Cochrane Central Register of Controlled Trials, EMBASE, China
National Knowledge Infrastructure, Wanfang and Weipu Databases for all RCT studies that investigated the treatments of up to February 2016. The following search terms were applied: ("acute promyelocytic leukemia" OR "APL" OR "M3") and ("treatment" "therapy" OR "medicine" OR "chemotherapy" OR "CT" OR "alltrans retinoic acid" OR "ATRA" OR "arsenic trioxide" OR “ATO” OR "Realgar-Indigo naturalis formula” OR "RIF") and ("randomized controlled trials" OR "RCT") without language restriction. The studies enrolled in the current network meta-analysis meet the following criteria: patients with newly diagnosed adults of APL; interventions with standard dose and duration of CT,

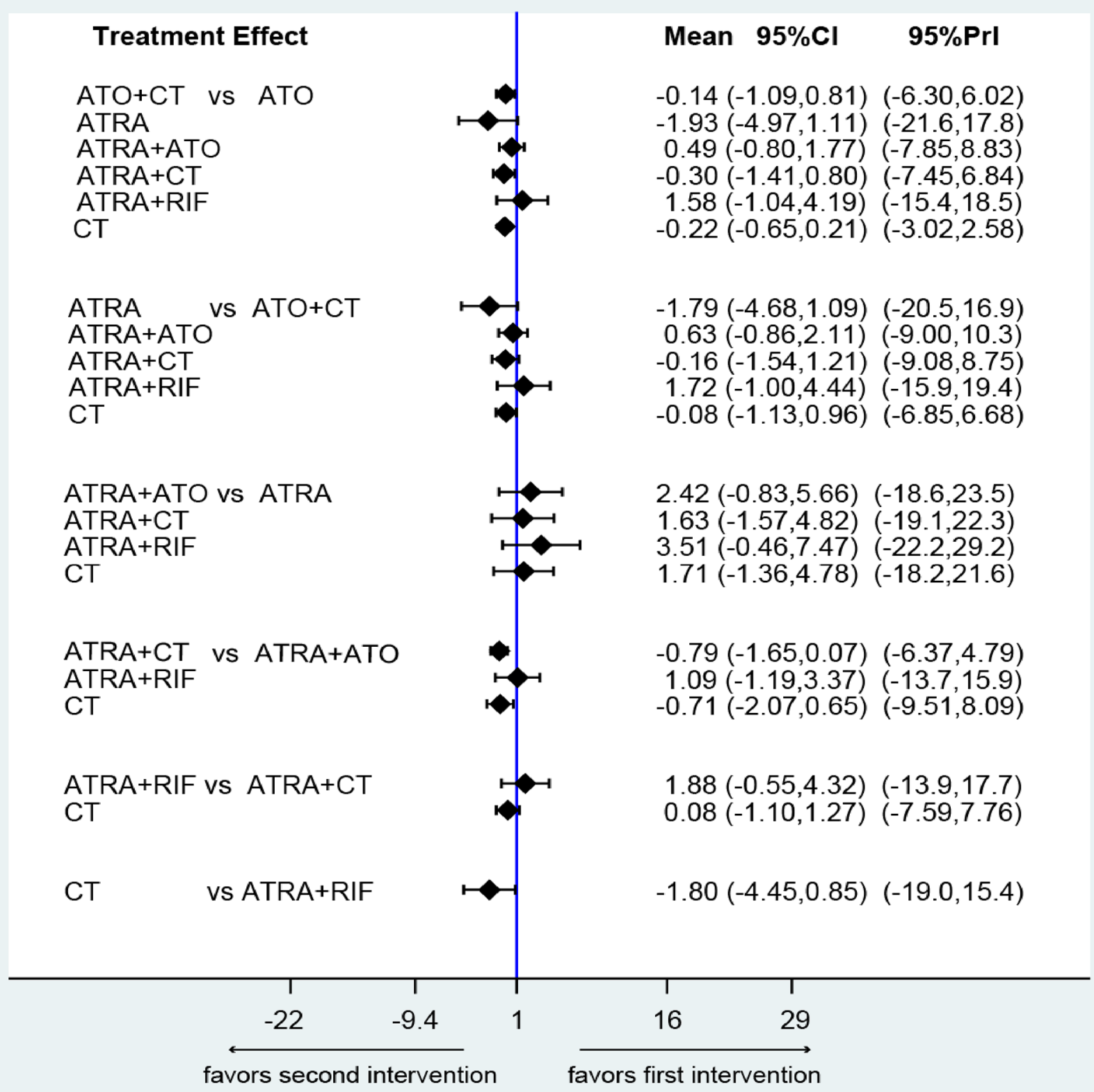

Figure 5: Confidence interval plot for the network analysis on a logarithmic scale. The black solid lines represent the confidence interval for summary odds ratios for each comparison. The blue line is the line of no effect (odds ratio equal to 1). 


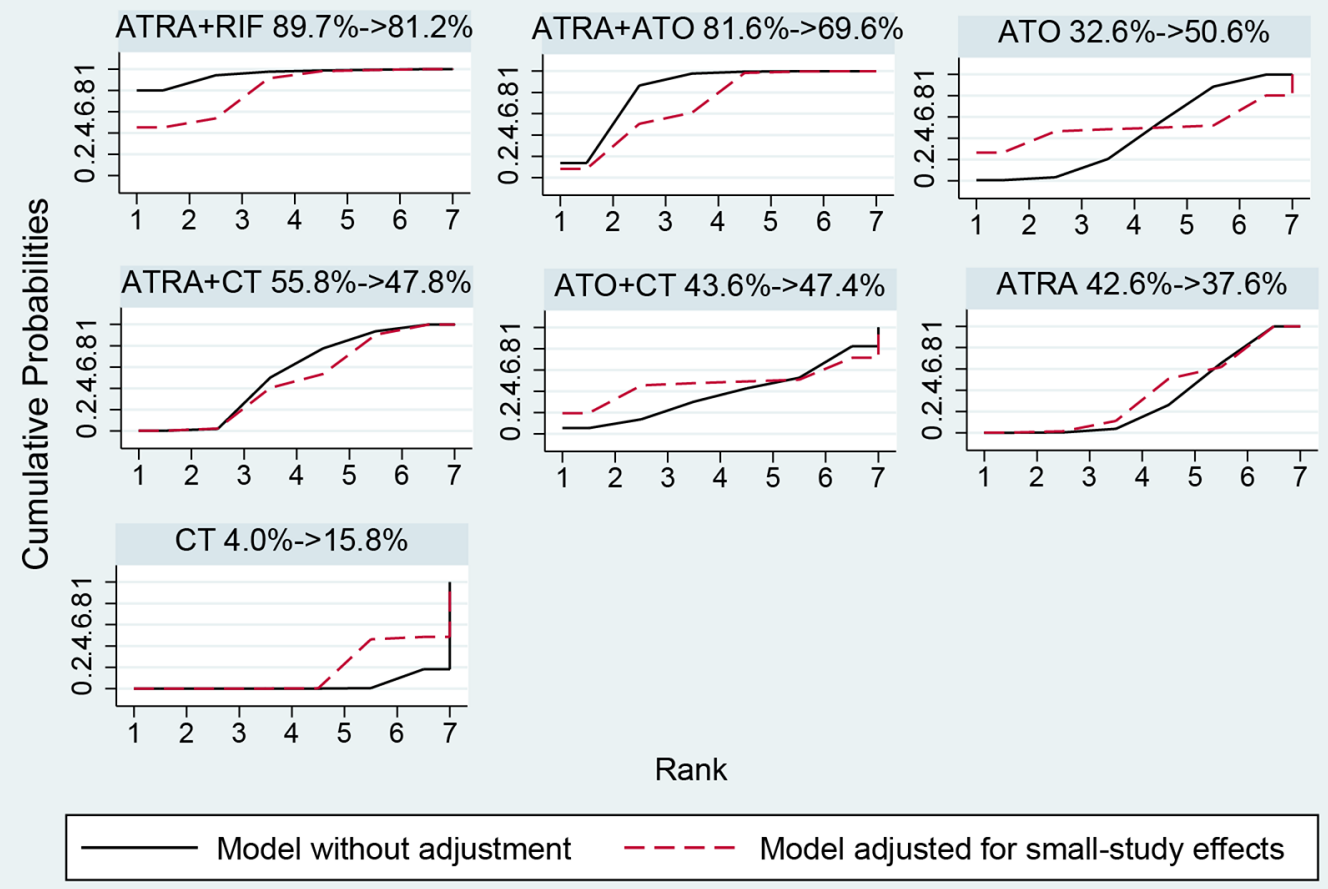

The Ability to Obtain the best EFS (2-year)

Figure 6: Surface under the cumulative ranking curves for the treatments in event free survival. Black solid lines correspond to the unadjusted model and red dashed lines to the adjusted for small effects model.

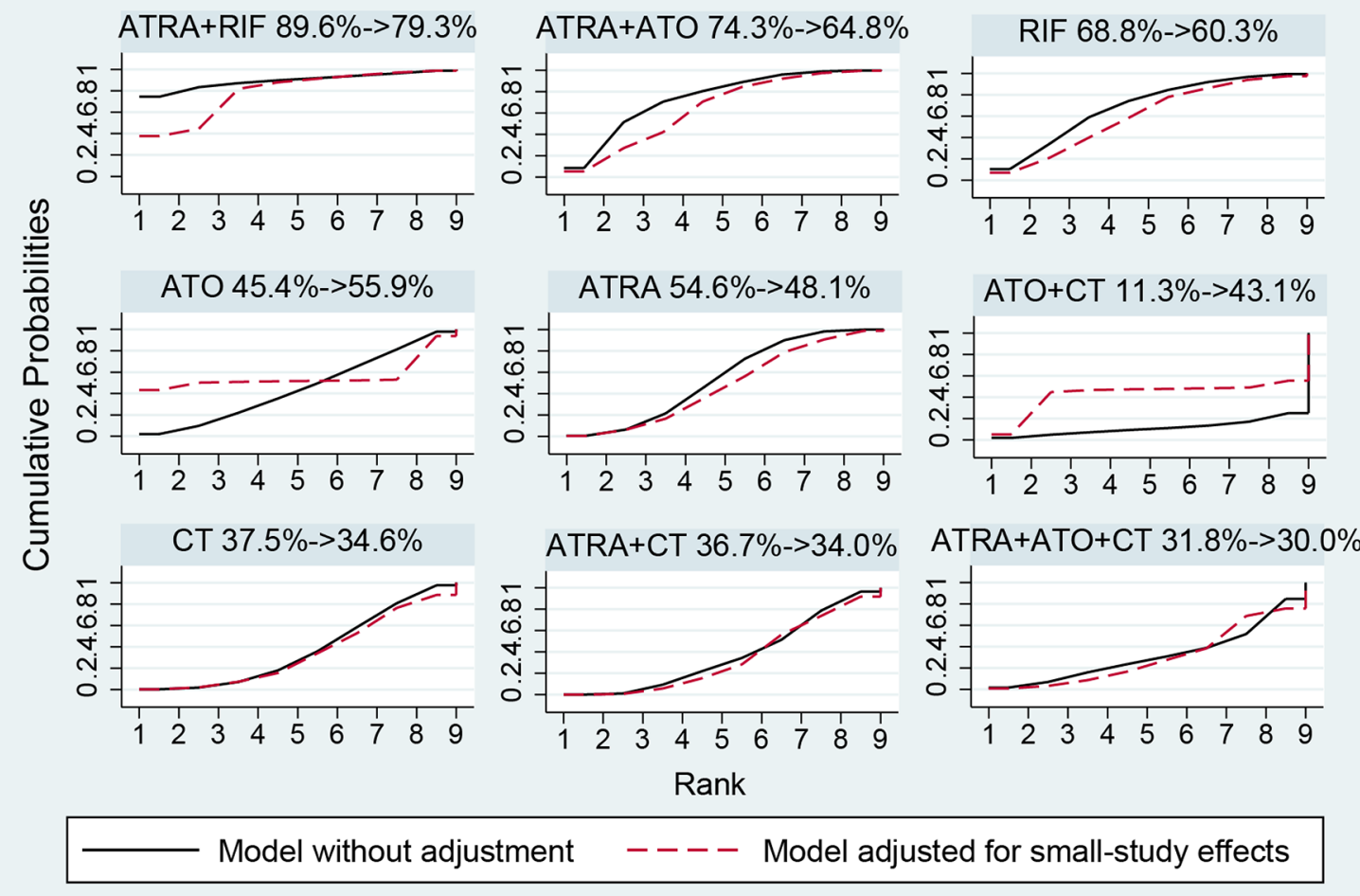

The Ability to acquire Complete Remission

Figure 7: Surface under the cumulative ranking curves for the treatments in complete remission. Black solid lines correspond to the unadjusted model and red dashed lines to the adjusted for small effects model. 


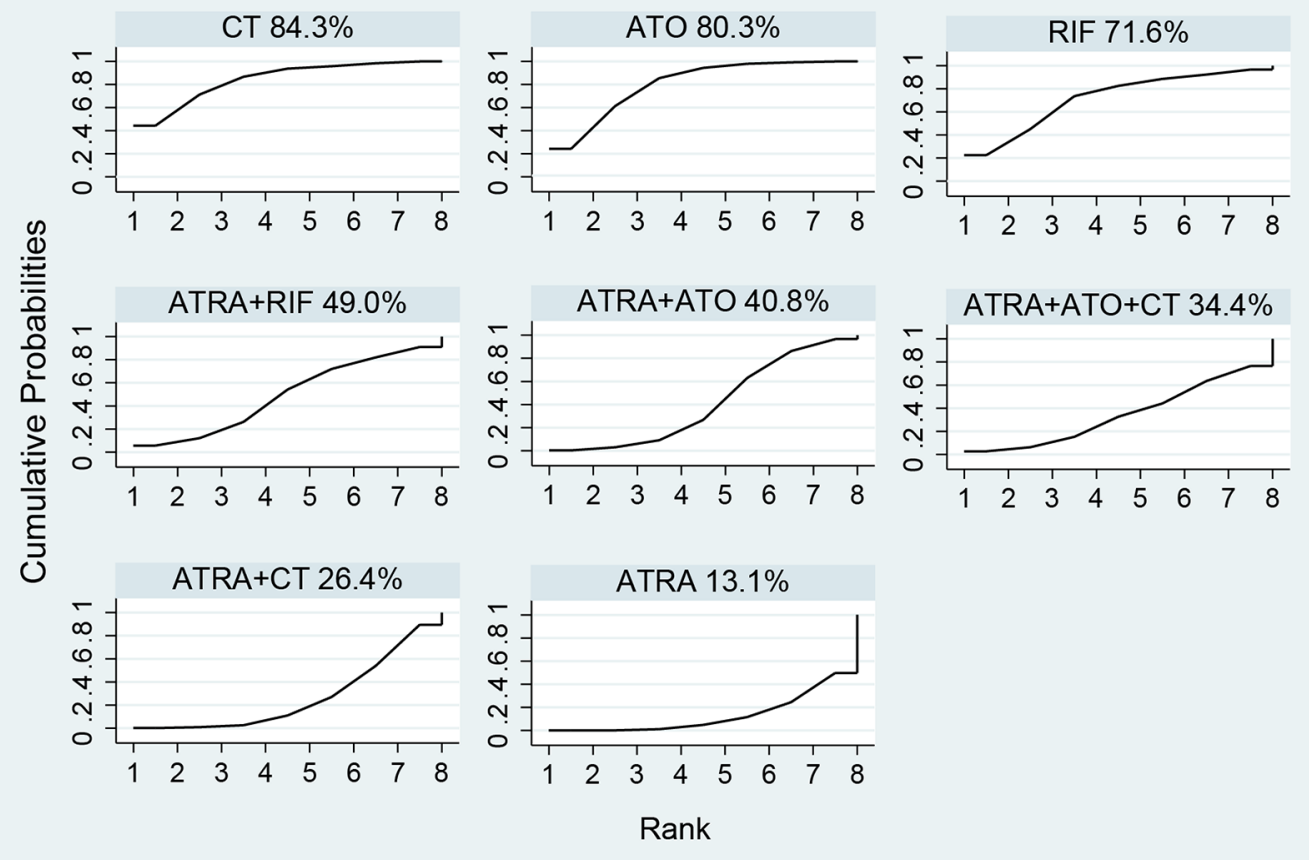

The Ability to Avoid Differentiation Syndrome

Figure 8: Surface under the cumulative ranking curves for the treatments in differentiation syndrome.

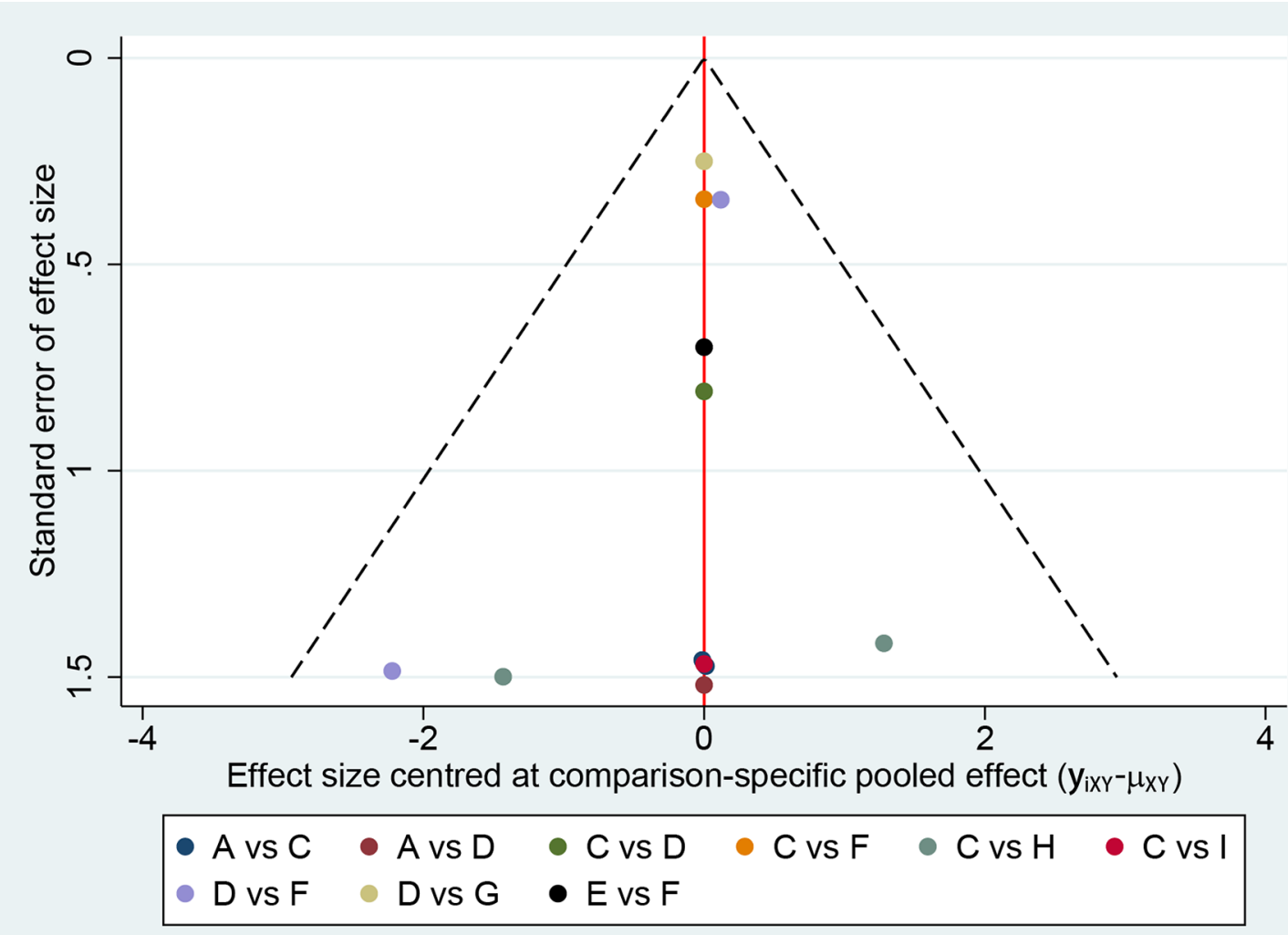

Figure 9: Comparison-adjusted funnel plot for the network meta-analysis. The red line suggests the null hypothesis that the study-specific effect sizes do not differ from the respective comparison-specific pooled effect estimates. Different colors represent different comparisons. 
ATRA, ATO or RIF in the induction therapy; comparisons of age, gender, white blood cells count, and follow-up of more than 2 years; outcomes of complete remission (CR), early death (ED), remission time (RT), event free survival (EFS), hepatic toxicity (HT) and differentiation syndrome (DS); study design is randomized controlled trial. The exclusion criteria were: duplicated publications; studies with insufficient data; with big difference in characteristics between groups; retrospective studies; low quality clinical trials.

\section{Data extraction and quality assessment}

The relevant data were extracted from the articles by two investigators. The following information was obtained: name, date, place, report author, and country or study group of the clinical trials; baseline characteristics including age, gender, ethnicity, interventions across the groups; results of CR rate, ED event, RT, EFS rate, and adverse event including HT and DS. The Cochrane Collaboration's tool was adopted to assess the risk of bias in these randomized trials [55]. The risk of bias covers 7 domains, including random sequence generation, allocation concealment, blinding of participants and personnel, blinding of outcome assessment, incomplete outcome data, selective reporting, and other bias. Any disagreement was discussed with a third investigator until a consensus was reached.

\section{Statistical analysis}

The network meta-analysis was performed by STATA 14.0 (Stata Corp, College Station, TX). 2-year EFS rate was defined as the primary endpoint. CR rate, ED event, RT, HT and DS were defined as the secondary endpoints. Relative risk (RR) with 95\% confidence intervals (CIs) was calculated using the random-effects model or fixed-effects model for investigating treatment effects $[56,57]$. $Z$ test was conducted to assess the significance of overall effect size. A $P$ value of less than 0.05 was considered statistically significant.

A network plot was produced to represent the overall information of the trials included in the analysis. Nodes size represents the number of trials for each treatment and lines thickness represents the number of available direct comparisons [58]. The contribution of each direct comparison to each network estimate was calculated according to the variance of the direct treatment effect and the network structure, later summarized in a contribution plot [59].

After constructing a heterogeneity matrix, the frequentist method was applied to the fitted meta-regression model. The model covariates as the basic parameters and assumed that heterogeneity is independent of the comparison between effect sizes from multi-arm studies [60]. Inconsistency refers to the differences between direct and various indirect effects estimated for the same comparison.
We investigated possible sources of inconsistency using inconsistency factor (IF) among studies in each closed loop. If the $95 \%$ CIs of $I F$ values are truncated at zero or the $P$ value of z-test is higher than 0.05 , it indicates that there is no statistically significant inconsistency [61]. Note that IF is the logarithm of the ratio of two odds ratios $(R o R)$ from direct and indirect evidence in the loop. RoR values truncate at one would also indicate consistency [62]. A forest plot of the estimated summary effects, along with confidence intervals and corresponding predictive intervals (PrI) for all comparisons, summarizes the relative mean effects, the impact of heterogeneity and predictions on each comparison in one plot [63].

We estimated the probability of a treatment being ranked at a specific place according to the outcome using SUCRA (surface under the cumulative ranking curve). SUCRA is a simple transformation of the mean rank, providing a hierarchy of the treatments and accounts for the location and the variance of all relative treatment effects. The higher the SUCRA value is, the higher possible ranking of the treatment is. SUCRA was adjusted by a model of network meta-regression accounting for small-study effects, using the variance of the log-odds ratios as covariation [64].

The publication bias was evaluated by a 'comparison-adjusted' funnel plots whose horizontal axis presents the difference between study-specific effect sizes and the corresponding comparison-specific summary effect. The funnel plot should be symmetrical near the zero line if there is no publication bias [65].

\section{CONFLICTS OF INTEREST}

The authors have declared that no competing interests exist.

\section{FUNDING}

This work was supported by grants from the Shenzhen Municipal Government of China (Grant No.20150623, JCYJ20150330102720163), and Special Support Funds of Shenzhen for Introduced High-Level Medical Team. The funders had no role in study design, data collection and analysis, decision to publish, or preparation of the manuscript.

\section{REFERENCES}

1. Haferlach T, Gassmann W, Loffler H, Jurgensen C, Noak J, Ludwig WD, Thiel E, Haase D, Fonatsch C, Becher R. Clinical aspects of acute myeloid leukemias of the FAB types M3 and M4Eo. The AML Cooperative Group. Annals of hematology. 1993; 66:165-170.

2. Yu W, Sun B, Chen Z. [Effect of antisense oligodeoxynucleotide (ASODN) to PML-RAR alpha fusion 
gene on acute promyelocytic leukemia cell line NB4]. Zhonghua xue ye xue za $\mathrm{zhi}=$ Zhonghua xueyexue zazhi. 1998; 19:227-230.

3. Yu W, Sun B, Chen Z. [The relation between expression of PML-RAR alpha gene and effects of ATRA on proliferation and differentiation of NB4 cells]. Zhonghua yi xue za zhi. 1997; 77:745-749.

4. Hillestad LK. Acute promyelocytic leukemia. Acta medica Scandinavica. 1957; 159:189-194.

5. Bernard J, Mathe G, Boulay J, Ceoard B, Chome J. [Acute promyelocytic leukemia: a study made on 20 cases]. Schweizerische medizinische Wochenschrift. 1959; 89:604-608.

6. Wang ZY, Chen Z. Acute promyelocytic leukemia: from highly fatal to highly curable. Blood. 2008; 111:2505-2515.

7. Bernard J, Weil M, Boiron M, Jacquillat C, Flandrin G, Gemon MF. Acute promyelocytic leukemia: results of treatment by daunorubicin. Blood. 1973; 41:489-496.

8. Sanz MA, Jarque I, Martin G, Lorenzo I, Martinez J, Rafecas J, Pastor E, Sayas MJ, Sanz G, Gomis F. Acute promyelocytic leukemia. Therapy results and prognostic factors. Cancer. 1988; 61:7-13.

9. Sun GL. [Treatment of acute promyelocytic leukemia (APL) with all-trans retinoic acid (ATRA): a report of five-year experience]. Zhonghua zhong liu za zhi [Chinese journal of oncology]. 1993; 15:125-129.

10. Wang ZY, Chen Z, Huang W, Li XS, Lu JX, Huang LA, Zhang FQ, Gu LJ, Ouyang RR, Chen SJ. Problems existing in differentiation therapy of acute promyelocytic leukemia (APL) with all-trans retinoic acid (ATRA). Blood cells. 1993; 19:633-641; 642-637.

11. Ikeda Y, Yoshinaga K, Iki S, Ohbayashi Y, Urabe A. [Acute promyelocytic leukemia (APL) resulting in broad cerebral infarction during all-trans retinoic acid (ATRA) treatment]. [Rinsho ketsueki] The Japanese journal of clinical hematology. 1994; 35:183-187.

12. Fenaux P. Treatment of newly diagnosed APL. The best choice is not ATRA or chemotherapy but a combination of both. European APL Group. Leukemia. 1994; 8:S59-61; discussion S62.

13. Fenaux P. Results of APL 91 European trial combining ATRA and chemotherapy: presentation of APL 1993 trial. Leukemia. 1994; 8:S70-72.

14. Fenaux P, Chastang C, Degos L. Treatment of newly diagnosed acute promyelocytic leukemia (APL) by a combination of alltrans retinoic acid (ATRA) and chemotherapy. French APL Group. Leukemia. 1994; 8:S42-47.

15. Chen GQ, Shi XG, Tang W, Xiong SM, Zhu J, Cai X, Han ZG, Ni JH, Shi GY, Jia PM, Liu MM, He KL, Niu C, et al. Use of arsenic trioxide (As2O3) in the treatment of acute promyelocytic leukemia (APL): I. As2O3 exerts dosedependent dual effects on APL cells. Blood. 1997; 89:33453353.

16. Shen ZX, Chen GQ, Ni JH, Li XS, Xiong SM, Qiu QY, Zhu J, Tang W, Sun GL, Yang KQ, Chen Y, Zhou L,
Fang ZW, et al. Use of arsenic trioxide (As2O3) in the treatment of acute promyelocytic leukemia (APL): II. Clinical efficacy and pharmacokinetics in relapsed patients. Blood. 1997; 89:3354-3360.

17. Zhang TD, Chen GQ, Wang ZG, Wang ZY, Chen SJ, Chen Z. Arsenic trioxide, a therapeutic agent for APL. Oncogene. 2001; 20:7146-7153.

18. Raelson JV, Nervi C, Rosenauer A, Benedetti L, Monczak Y, Pearson M, Pelicci PG, Miller WH, Jr. The PML/RAR alpha oncoprotein is a direct molecular target of retinoic acid in acute promyelocytic leukemia cells. Blood. 1996; 88:2826-2832.

19. Chen GQ, Zhu J, Shi XG, Ni JH, Zhong HJ, Si GY, Jin XL, Tang W, Li XS, Xong SM, Shen ZX, Sun GL, Ma J. In vitro studies on cellular and molecular mechanisms of arsenic trioxide (As2O3) in the treatment of acute promyelocytic leukemia: As2O3 induces NB4 cell apoptosis with downregulation of Bcl-2 expression and modulation of PMLRAR alpha/PML proteins. Blood. 1996; 88:1052-1061.

20. Wang G, Li W, Cui J, Gao S, Yao C, Jiang Z, Song Y, Yuan CJ, Yang Y, Liu Z, Cai L. An efficient therapeutic approach to patients with acute promyelocytic leukemia using a combination of arsenic trioxide with low-dose all-trans retinoic acid. Hematological oncology. 2004; 22:63-71.

21. Estey E, Garcia-Manero G, Ferrajoli A, Faderl S, Verstovsek S, Jones D, Kantarjian H. Use of all-trans retinoic acid plus arsenic trioxide as an alternative to chemotherapy in untreated acute promyelocytic leukemia. Blood. 2006; 107:3469-3473.

22. Aribi A, Kantarjian HM, Estey EH, Koller CA, Thomas DA, Kornblau SM, Faderl SH, Laddie NM, Garcia-Manero G, Cortes JE. Combination therapy with arsenic trioxide, all-trans retinoic acid, and gemtuzumab ozogamicin in recurrent acute promyelocytic leukemia. Cancer. 2007; 109:1355-1359.

23. Lu DP, Qiu JY, Jiang B, Wang Q, Liu KY, Liu YR, Chen SS. Tetra-arsenic tetra-sulfide for the treatment of acute promyelocytic leukemia: a pilot report. Blood. 2002; 99:3136-3143.

24. Wang L, Zhou GB, Liu P, Song JH, Liang Y, Yan XJ, Xu F, Wang BS, Mao JH, Shen ZX, Chen SJ, Chen Z. Dissection of mechanisms of Chinese medicinal formula RealgarIndigo naturalis as an effective treatment for promyelocytic leukemia. Proceedings of the National Academy of Sciences of the United States of America. 2008; 105:4826-4831.

25. Xiang-Xin L, Lu-Qun W, Hao L, Xiao-Peng H, FangLin L, Ling-Ling W, Xue-Liang C, Ming H. Clinical study on prospective efficacy of all-trans Acid, realgarindigo naturalis formula combined with chemotherapy as maintenance treatment of acute promyelocytic leukemia. Evidence-based complementary and alternative medicine. 2014; 2014:987560.

26. Zhu HH, Huang XJ. Oral arsenic and retinoic acid for nonhigh-risk acute promyelocytic leukemia. The New England journal of medicine. 2014; 371:2239-2241. 
27. Fenaux P, Le Deley MC, Castaigne S, Archimbaud E, Chomienne C, Link H, Guerci A, Duarte M, Daniel MT, Bowen D. Effect of all transretinoic acid in newly diagnosed acute promyelocytic leukemia. Results of a multicenter randomized trial. European APL 91 Group. Blood. 1993; 82:3241-3249.

28. Fenaux P, Chastang C, Chomienne C, Degos L. Tretinoin with chemotherapy in newly diagnosed acute promyelocytic leukaemia. European APL Group. Lancet. 1994; 343:1033.

29. Fenaux P, Chastang C, Chomienne C, Castaigne S, Sanz M, Link H, Lowenberg B, Fey M, Archim-Baud E, Degos L. Treatment of newly diagnosed acute promyelocytic leukemia (APL) by all transretinoic acid (ATRA) combined with chemotherapy: The European experience. European APL Group. Leukemia \& lymphoma. 1995; 16:431-437.

30. Tallman MS, Andersen JW, Schiffer CA, Appelbaum FR, Feusner JH, Ogden A, Shepherd L, Willman C, Bloomfield CD, Rowe JM, Wiernik PH. All-trans-retinoic acid in acute promyelocytic leukemia. The New England journal of medicine. 1997; 337:1021-1028.

31. De Botton S, Dombret H, Sanz M, Miguel JS, Caillot D, Zittoun R, Gardembas M, Stamatoulas A, Conde E, Guerci A, Gardin C, Geiser K, Makhoul DC, et al. Incidence, clinical features, and outcome of all transretinoic acid syndrome in 413 cases of newly diagnosed acute promyelocytic leukemia. The European APL Group. Blood. 1998; 92:2712-2718.

32. Fenaux P, Chastang C, Chevret S, Sanz M, Dombret H, Archimbaud E, Fey M, Rayon C, Huguet F, Sotto JJ, Gardin C, Makhoul PC, Travade P, et al. A randomized comparison of all transretinoic acid (ATRA) followed by chemotherapy and ATRA plus chemotherapy and the role of maintenance therapy in newly diagnosed acute promyelocytic leukemia. The European APL Group. Blood. 1999; 94:1192-1200.

33. Niu C, Yan H, Yu T, Sun HP, Liu JX, Li XS, Wu W, Zhang FQ, Chen Y, Zhou L, Li JM, Zeng XY, Yang RR, et al. Studies on treatment of acute promyelocytic leukemia with arsenic trioxide: remission induction, follow-up, and molecular monitoring in 11 newly diagnosed and 47 relapsed acute promyelocytic leukemia patients. Blood. 1999; 94:3315-3324.

34. Zhang X, Yang L, Qiao Z. [An analysis of the therapeutic effects and reactions in treating acute promyelocytic leukemia with intravenous arsenic trioxide or all-trans retinoic acid]. Zhonghua nei ke za zhi. 1999; 38:113-115.

35. Fenaux P, Chevret S, Guerci A, Fegueux N, Dombret H, Thomas X, Sanz M, Link H, Maloisel F, Gardin C, Bordessoule D, Stoppa AM, Sadoun A, et al. Long-term follow-up confirms the benefit of all-trans retinoic acid in acute promyelocytic leukemia. European APL group. Leukemia. 2000; 14:1371-1377.

36. Tallman MS, Andersen JW, Schiffer CA, Appelbaum FR, Feusner JH, Woods WG, Ogden A, Weinstein H, Shepherd L, Willman C, Bloomfield CD, Rowe JM,
Wiernik PH. All-trans retinoic acid in acute promyelocytic leukemia: long-term outcome and prognostic factor analysis from the North American Intergroup protocol. Blood. 2002; 100:4298-4302.

37. de Botton S, Chevret S, Coiteux V, Dombret H, Sanz M, San Miguel J, Caillot D, Vekhoff A, Gardembas M, Stamatoulas A, Conde E, Guerci A, Gardin C, et al. Early onset of chemotherapy can reduce the incidence of ATRA syndrome in newly diagnosed acute promyelocytic leukemia (APL) with low white blood cell counts: results from APL 93 trial. Leukemia. 2003; 17:339-342.

38. JH Ren FL, XN Guo, Ying Wang, JN Zhang, Yan Wang, ZR Dong. A Clinical trial of the conbination of Retinoic Acid, Arsenic Trioxide and Chemotherapy. Chin J Hematol. 2004; 25:437-438.

39. Shen ZX, Shi ZZ, Fang J, Gu BW, Li JM, Zhu YM, Shi JY, Zheng PZ, Yan H, Liu YF, Chen Y, Shen Y, Wu W, et al. All-trans retinoic acid/As2O3 combination yields a high quality remission and survival in newly diagnosed acute promyelocytic leukemia. Proceedings of the National Academy of Sciences of the United States of America. 2004; 101:5328-5335.

40. Ades L, Chevret S, De Botton S, Thomas X, Dombret H, Beve B, Sanz M, Guerci A, Miguel JS, Dela Serna J, Garo C, Stoppa AM, Reman O, et al. Outcome of acute promyelocytic leukemia treated with all trans retinoic acid and chemotherapy in elderly patients: the European group experience. Leukemia. 2005; 19:230-233.

41. Qian L. Phase II clinical trial of compound Huangdai tablet in newly dignosed acute promyeocytic leukemia. Chin J Hematol. 2006; 27:801-804.

42. Gregory J, Kim H, Alonzo T, Gerbing R, Woods W, Weinstein H, Shepherd L, Schiffer C, Appelbaum F, Willman C, Wiernik P, Rowe J, Tallman M, Feusner J. Treatment of children with acute promyelocytic leukemia: results of the first North American Intergroup trial INT0129. Pediatric blood \& cancer. 2009; 53:1005-1010.

43. Douer D, Zickl LN, Schiffer CA, Appelbaum FR, Feusner JH, Shepherd L, Willman CL, Bloomfield CD, Paietta E, Gallagher RE, Park JH, Rowe JM, Wiernik PH, Tallman MS. All-trans retinoic acid and late relapses in acute promyelocytic leukemia: very long-term follow-up of the North American Intergroup Study I0129. Leukemia research. 2013; 37:795-801.

44. Lo-Coco F, Avvisati G, Vignetti M, Thiede C, Orlando SM, Iacobelli S, Ferrara F, Fazi P, Cicconi L, Di Bona E, Specchia G, Sica S, Divona M, et al. Retinoic acid and arsenic trioxide for acute promyelocytic leukemia. The New England journal of medicine. 2013; 369:111-121.

45. Zhu HH, Wu DP, Jin J, Li JY, Ma J, Wang JX, Jiang H, Chen SJ, Huang XJ. Oral Tetra-Arsenic Tetra-Sulfide Formula Versus Intravenous Arsenic Trioxide As First-Line Treatment of Acute Promyelocytic Leukemia: A Multicenter Randomized Controlled Trial. Journal of Clinical Oncology. 2013; 31:4215-4221. 
46. Efficace F, Mandelli F, Avvisati G, Cottone F, Ferrara F, Di Bona E, Specchia G, Breccia M, Levis A, Sica S, Finizio O, Kropp MG, Fioritoni G, et al. Randomized phase III trial of retinoic acid and arsenic trioxide versus retinoic acid and chemotherapy in patients with acute promyelocytic leukemia: health-related quality-of-life outcomes. Journal of clinical oncology. 2014; 32:3406-3412.

47. Burnett AK, Russell NH, Hills RK, Bowen D, Kell J, Knapper S, Morgan YG, Lok J, Grech A, Jones G, Khwaja A, Friis L, McMullin MF, et al. Arsenic trioxide and all-trans retinoic acid treatment for acute promyelocytic leukaemia in all risk groups (AML17): results of a randomised, controlled, phase 3 trial. The Lancet Oncology. $2015 ; 16: 1295-1305$.

48. Wang H, Chen XY, Wang BS, Rong ZX, Qi H, Chen HZ. The efficacy and safety of arsenic trioxide with or without all-trans retinoic acid for the treatment of acute promyelocytic leukemia: a meta-analysis. Leukemia research. 2011; 35:1170-1177.

49. Chen L, Wang J, Hu X, Xu X. Meta-analysis of all-trans retinoic acid-linked arsenic trioxide treatment for acute promyelocytic leukemia. Hematology. 2014; 19:202-207.

50. Ma H, Yang J. Insights into the All-trans-Retinoic Acid and Arsenic Trioxide Combination Treatment for Acute Promyelocytic Leukemia: A Meta-Analysis. Acta haematologica. 2015; 134:101-108.

51. O'Donnell MR, Tallman MS, Abboud CN, Altman JK, Appelbaum FR, Arber DA, Attar E, Borate U, Coutre SE, Damon LE, Lancet J, Maness LJ, Marcucci G, et al. Acute myeloid leukemia, version 2.2013. Journal of the National Comprehensive Cancer Network. 2013; 11: 1047-1055.

52. Mathews V, George B, Lakshmi KM, Viswabandya A, Bajel A, Balasubramanian P, Shaji RV, Srivastava VM, Srivastava A, Chandy M. Single-agent arsenic trioxide in the treatment of newly diagnosed acute promyelocytic leukemia: durable remissions with minimal toxicity. Blood. 2006; 107:2627-2632.

53. Ghavamzadeh A, Alimoghaddam K, Ghaffari SH, Rostami S, Jahani M, Hosseini R, Mossavi A, Baybordi E, Khodabadeh A, Iravani M, Bahar B, Mortazavi Y, Totonchi M, Aghdami N. Treatment of acute promyelocytic leukemia with arsenic trioxide without ATRA and/or chemotherapy. Annals of oncology. 2006; 17:131-134.
54. Keyhani M. Use of arsenic trioxide as a first-line single agent in the treatment of acute promyelocytic leukemia. Journal of clinical oncology. 2012; 30:217; author reply 218-220; discussion 220-212.

55. Higgins JP, Altman DG, Gotzsche PC, Juni P, Moher D, Oxman AD, Savovic J, Schulz KF, Weeks L, Sterne JA. Cochrane Bias Methods G, Cochrane Statistical Methods G. The Cochrane Collaboration's tool for assessing risk of bias in randomised trials. Bmj. 2011; 343:d5928.

56. Mantel N, Haenszel W. Statistical aspects of the analysis of data from retrospective studies of disease. Journal of the National Cancer Institute. 1959; 22:719-748.

57. DerSimonian R, Laird N. Meta-analysis in clinical trials. Controlled clinical trials. 1986; 7:177-188.

58. Salanti G. Indirect and mixed-treatment comparison, network, or multiple-treatments meta-analysis: many names, many benefits, many concerns for the next generation evidence synthesis tool. Research synthesis methods. 2012; 3:80-97.

59. Krahn U, Binder H, Konig J. A graphical tool for locating inconsistency in network meta-analyses. BMC medical research methodology. 2013; 13:35.

60. Lumley T. Network meta-analysis for indirect treatment comparisons. Statistics in medicine. 2002; 21:2313-2324.

61. Dias S, Welton NJ, Caldwell DM, Ades AE. Checking consistency in mixed treatment comparison meta-analysis. Statistics in medicine. 2010; 29:932-944.

62. Donegan S, Williamson P, D'Alessandro U, Tudur Smith C. Assessing key assumptions of network metaanalysis: a review of methods. Research synthesis methods. 2013; 4:291-323.

63. Jackson D, White IR, Riley RD. Quantifying the impact of between-study heterogeneity in multivariate meta-analyses. Statistics in medicine. 2012; 31:3805-3820.

64. Riley RD, Higgins JP, Deeks JJ. Interpretation of random effects meta-analyses. Bmj. 2011; 342:d549.

65. Peters JL, Sutton AJ, Jones DR, Abrams KR, Rushton L. Performance of the trim and fill method in the presence of publication bias and between-study heterogeneity. Statistics in medicine. 2007; 26:4544-4562. 